\title{
Is HAM/3 (Hydrogenic Atoms in Molecules, Version 3) a Semiempirical Version of DFT (Density Functional Theory) for Ionization Processes?
}

\author{
Yuji Takahata $^{*, a}$, Delano P. Chong ${ }^{b}$ and Maxmiliano Segala ${ }^{c}$ \\ ${ }^{a}$ Instituto de Química, Universidade Estadual de Campinas, CP 6154, 13084-862 Campinas - SP, Brazil \\ ${ }^{b}$ Department of Chemistry, 2036 Main Mall, University of British Columbia, Vancouver, B.C., Canada, V6T 1Z1 \\ ${ }^{c}$ Universidade Estadual do Rio Grande do Sul, Rua Rivadavia Correa,825, \\ 97573-011 Santana do Livramento - RS, Brazil
}

\begin{abstract}
Nós calculamos os potenciais de ionização verticais (VIPs) de nove moléculas pequenas, bem como, os potenciais de uracil e do $\mathrm{C}_{2} \mathrm{~F}_{2}$ usando diferentes métodos: i) semi-empírico HAM/3; ii) semi-empírico AM1; iii) não empírico Teoria do Funcional de Densidade (TFD) com os modelos uDI(B88-P86)/cc-pVTZ e $-\varepsilon(\mathrm{SAOP}) / \mathrm{TZP}$; iv) ab initio HF/cc-pVTZ. Os resultados numéricos obtidos com HAM/3 são mais próximos dos resultados obtidos com o TFD do que o Hartree-Fock (HF). Nós também calculamos as energias de ligação de elétrons do caroço (CEBE) da anilina, nitrobenzeno, e p-nitroanilina com o HAM/3 e a TFD empregando o método $\triangle E$. O modelo de DFT designado como $\Delta \mathrm{E}_{\mathrm{KS}}$ (PW86-PW91)/TZP produziu resultados precisos de CEBE, com desvio médio absolutos de $0,14 \mathrm{eV}$. Enquanto que a magnitude absoluta dos $\mathrm{CEBEs}$ calculados pelo método $\mathrm{HAM} / 3$ tem um erro de menos de $3 \mathrm{eV}$, os deslocamentos químicos ( $\triangle \mathrm{CEBE}$ ) têm erros menores que $0,55 \mathrm{eV}$. Mesmo que os resultados de CEBE não apresentem uma resposta definitiva à pergunta do título, as tendências nos VIPs indicam que o HAM/3 não se aproxima do TFD com potenciais de troca-correlação precisos, mas indicam uma proximidade com funcionais semelhantes ao B88-P86.
\end{abstract}

We calculated valence-electron vertical ionization potentials (VIPs) of nine small molecules, plus uracil and $\mathrm{C}_{2} \mathrm{~F}_{4}$, by several different methods: semiempirical HAM/3 and AM1 methods, different nonempirical DFT models such as uDI(B88-P86)/cc-pVTZ and $-\varepsilon(\mathrm{SAOP}) / \mathrm{TZP}$, and $a b$ initio Hartree-Fock (HF)/cc-pVTZ. HAM/3 reproduced numerical values more closely to those calculated by the nonempirical DFTs than to those obtained by HF method. Core-electron binding energies (CEBEs) of aniline, nitrobenzene and p-nitro aniline, were also calculated by HAM/3 and nonempirical $\Delta F T$ using DE method. A nonempirical DFT model, designated as $\Delta \mathrm{E}_{\mathrm{KS}}$ (PW86-PW91)/TZP model, resulted accurate CEBEs (average absolute deviation of $0.14 \mathrm{eV}$ ) with high efficiency. Although absolute magnitude of HAM/3 CEBEs has error as much as $3 \mathrm{eV}$, the error in the chemical shifts $\triangle \mathrm{CEBE}$ is much smaller at $0.55 \mathrm{eV}$. While the CEBE results do not lead to any definite answer to the question in the title, the trends in valence-electron VIPs indicate that HAM/3 does not approximate DFT with accurate exchange-correlation potentials, but seems to simulate approximate functionals such as B88-P86.

Keywords: HAM/3, DFT, vertical ionization potential, CEBE, ESCA

\section{Introduction}

The semiempirical molecular orbital (MO) method known as Hydrogenic Atoms in Molecules, Version 3 (HAM/3) was developed by group of Lindholm and coworkers in $1977 .{ }^{1}$ The method has been successfully applied to the calculation of mainly vertical ionization potentials (VIPs), excitation energies, and electron

\footnotetext{
* e-mail: taka@iqm.unicamp.br
}

affinities of wide variety of molecules. Some selected works are listed in references 2-7. However, extensions of HAM/3 to the calculation of X-ray emission spectra, ${ }^{8}$ Auger electron spectra, ${ }^{9}$ valence-electron shake-up satellites, ${ }^{10}$ core-electron shake-up satellites, ${ }^{11}$ and relative intensities for valence region of X-ray photoelectron spectra will not be discussed in this paper. The theoretical foundation of HAM $/ 3$ has been described in detail in the book of Lindholm and Asbrink. ${ }^{12}$ According to the authors, theoretical foundation of HAM/3 method is based on 
density functional theory (DFT). ${ }^{13,14}$ In other words, HAM/3 was considered to be a semiempirical version of DFT. In their book, Parr and Yang ${ }^{15}$ called attention to the HAM model being a semiempirical version of the Kohn-Sham method.

The increasing popularity of DFT in the last decade is quite remarkable. DFT is one of the most promising theoretical methods to study electronic structure of medium and relatively large molecular system as well as solid state in high accuracy. Although there are empirical parameters in most choices of the exchange-correlation functional $\mathrm{E}_{\mathrm{xc}}$, the parameters are assumed to be universal for all systems (and hence not empirical for each element), and consequently DFT calculations are often considered to be $a$ priori, firstprinciple, or nonempirical. The advancement of DFT is due to development of more and more reliable exchangecorrelation functionals $\mathrm{E}_{\mathrm{xc}}$, together with availability of powerful computers with relatively low cost. However, there still remains an area in which a semiempirical method such as HAM/3 can play. Computer times of calculation for a large molecular system by HAM/ 3 are orders of magnitude smaller than nonempirical DFT calculation. There are occasions when calculation of approximate molecular properties of a large number of molecules is desired in short time. In such cases, a semiempirical method is the natural method of choice. The object of the present paper is to investigate numerically to determine whether or not HAM/3 is really a semiempirical version of DFT for ionization processes. We therefore calculate vertical ionization potentials (VIPs) of outer valence electrons as well as coreelectron binding energies (CEBEs) of some molecules for comparable studies.

Before we begin, let us briefly review the theoretical studies of VIPs and CEBEs. Early studies of VIPs, using semiempirical (such as CNDO, MINDO, AM1, etc.) or $a b$ initio Hartree-Fock (HF) methods, rely on Koopmans' theorem (KT). HAM/3 is an exception, using a simplified version of Slater's transition-state model ${ }^{16}$ called diffuse ionization (DI) for VIPs. ${ }^{1}$ On the other hand, a number of DFT calculations of VIPs have been performed previously. Initial studies ${ }^{17}$ showed that the VIPs for the lowest cationic states of each symmetry can be computed quite well, with average absolute deviations (AADs) of $0.3 \mathrm{eV}$ from experiment, regardless of whether one uses local density approximation or generalized gradient approximations such as B88 ${ }^{18}-\mathrm{P}_{8} 6^{19}$ or PW86 ${ }^{20}$-PW91, ${ }^{21}$ and regardless of whether one uses Slater's transition-state method or total energy difference $\Delta \mathrm{E}$. However, the list of molecules has not been extensive enough. Shapley and Chong used the PW86-PW91 functional and calculated 181 VIPs of 41 molecules by $\Delta \mathrm{E}$ method. ${ }^{22}$ The overall AAD from experiment was $0.55 \mathrm{eV}$. The most important impact of that study is that many VIPs, even for the lowest cationic state of each symmetry, for perfluoro molecules were in error by over $2 \mathrm{eV}$ (even with several other functionals). More recently, Chong and his collaborator ${ }^{23}$ showed that the energies $\varepsilon_{\mathrm{k}}$ of the outer-valence occupied Kohn-Sham orbitals gave approximate relaxed VIPs better than KT. Excellent agreement between $-\varepsilon_{\mathrm{k}}$ of outer-valence KohnSham MOs for $\mathrm{N}_{2}, \mathrm{CO}, \mathrm{HF}$ and $\mathrm{H}_{2} \mathrm{O}$ and experimental VIPs of the molecules were obtained, especially when accurate $\mathrm{V}_{\mathrm{xc}}$ was used, the average absolute deviation from experiment being less than $0.1 \mathrm{eV}$. In addition, calculations of 64 molecules were performed with the approximate $\mathrm{V}_{\mathrm{xc}}$ known as the statistical averaging of orbital potentials (SAOP). Reasonable agreement between $-\varepsilon_{k}$ (SAOP) and the outer valence VIPs (including many perhalo molecules) was found, with AAD of $0.4 \mathrm{eV}$, much better than KT with HF MOs. In this study, we shall designate the use of $-\varepsilon_{k}$ of Kohn-Sham orbital k (instead of Hartree-Fock orbital) to approximate VIP $_{\mathrm{k}}$ as meta-Koopmans' theorem (mKT).

Let us now turn to CEBEs. Since the early days of development of experimental technique of X-ray photoelectron spectroscopy, the electrostatic potential models or the thermochemical equivalent-core approximation, ${ }^{24}$ were used to interpret chemical shifts of CEBEs. Since then, several reviews have been published. ${ }^{25}$ In a potential model, for instance, the chemical shift is related to the atomic charge of the atom concerned and to those of surrounding atoms. There are empirical parameters that have to be determined by a least-squares fit to the experimental data in the model. Hence, the potential model can be called as an empirical model. There is fairly good correlation between observed and calculated chemical shift for many cases. However, there are cases where correlation is poor, depending on type of molecules treated. The semiempirical HAM/3 gives the CEBE directly as the difference between the ground-state molecule and the corehole cation. Chong ${ }^{26}$ compared CEBEs of a variety of molecules calculated by HAM/3 with observed ones. A persistent error associated with $\mathrm{C}-\mathrm{H}$ bonds was also reported. ${ }^{26}$ Recently, Chong ${ }^{27}$ proposed a method that enabled one to calculate accurate CEBEs by the densityfunctional theory. The method employs an unrestricted generalized transition-state (uGTS) model. ${ }^{28}$ Pulfer et al. have confirmed the reliability of the method with a total of seventy-six cases. ${ }^{29}$ More recently, a more reliable method, called $\Delta \mathrm{E}_{\mathrm{KS}}(\mathrm{PW} 86-\mathrm{PW} 91) / \mathrm{cc}-\mathrm{pCVTZ}$, was found by Cavigliasso and Chong. ${ }^{30}$ In the shorthand notation, $\Delta \mathrm{E}_{\mathrm{KS}}$ is the difference in the total energies $\mathrm{E}$ 's of coreionized cation and neutral parent molecule calculated by DFT using correlation consistent polarized core-valence 
triple zeta (cc-pCVTZ) basis set; PW86 is Perdew-Wang 1986 exchange functional, ${ }^{20}$ and PW91 is Perdew-Wang 1991 correlation functional. ${ }^{21}$ They used a modified version of DeMon computational package ${ }^{31}$ for the calculations. The initial high accuracy of molecular CEBEs, with AAD of only $0.15 \mathrm{eV}$ for 32 cases, was confirmed later with a total of 78 cases. ${ }^{32}$ An extensive review of DFT calculation of CEBE has been given in a chapter contributed by Chong. ${ }^{33}$ In this chapter, he also proposed the use of Amsterdam Density Functional (ADF) package ${ }^{34}$ for calculation of accurate CEBEs, because localizing a core hole is much easier with ADF than with other program such as DeMon.

\section{Method}

In this work, we calculate the VIPs of nine small molecules, as well as uracil and $\mathrm{C}_{2} \mathrm{~F}_{4}$, by several different methods: HAM/3, two models within nonempirical DFT, ab initio $\mathrm{HF}^{35}$ and the semiempirical MO method called Austin Model, Version 1 (AM1). ${ }^{36}$ In the first DFT method studied here, ionization energies of a system (neutral molecule M) can be calculated employing an approximate version of Slater's transition state (TS) method, in which one half electron is removed from the system. Absolute values of occupied MO energies of the species $\mathrm{M}^{+0.5}$ give the ionization energies. The HAM/3 calculations were performed with the computer program purchased from QCPE. ${ }^{37}$ In calculations of VIPs of the molecules by HAM/ 3 using the keyword PES, the restricted diffuse ionization (rDI) model was automatically employed. This model is the first model and it is designated as HAM/3 (rDI). The rDI model is a simplification of Slater's transition state method, by distributing the +0.5 charge over all the valence MOs, with electrons with $\alpha$ and $\beta$ spins occupying the same spatial orbitals. We also calculated negative of k-th molecular orbital energy $\left(-\varepsilon_{k}\right)$ of a neutral form of the nine small molecules by HAM/3 for the sake of comparison. This is the second model and it is designated as HAM/3 $\left(-\varepsilon_{k}\right)$. The negative of $\mathrm{k}$-th molecular orbital energy $\left(-\varepsilon_{\mathrm{k}}\right)$ of a neutral molecule would represent KT-like ionization potential. One nonempirical DFT model for calculation of valence electron VIPs is unrestricted diffuse ionization (uDI) model, uDI(B88-P86)/cc-pVTZ, which is the third model and it is designated simply by uDI. The calculations were done with DeMon computational package. In uDI model, +0.5 charge is distributed only $\alpha$-spin valence MOs. We used the exchange-correlation potential labeled as B88P86, made from Becke's 1988 exchange functional ${ }^{18}$ and Perdew's 1986 correlation functional ${ }^{19}$ in the uDI calculations. We also calculated negative of $\mathrm{k}$-th molecular orbital energy $\left(-\varepsilon_{\mathrm{k}}\right)$ of a neutral form of the nine small molecules by nonempirical DFT(B88-P86)/cc-pVTZ, which is our fourth model. It is designated as DFT(B88P86)/cc-pVTZ(mKT). The other DFT model tested is $-\varepsilon(\mathrm{SAOP}) / \mathrm{TZP}(\mathrm{mKT})$, which is the fifth model and it is designated simply by SAOP, using the ADF program with a triple-zeta polarized (TZP) basis set of Slater-type orbitals. In SAOP, electron density is calculated with the exchange-correlation potential $\mathrm{V}_{\mathrm{xc}}^{\text {SAOP }}$ in SCF process, while energy is calculated with PW91x-PW91c functionals. ${ }^{21}$ In HF/cc-pVTZ (6 ${ }^{\text {th }}$ model) and AM1 ( $7^{\text {th }}$ model) calculations with Gaussian 94 program, ${ }^{38} \mathrm{KT}$ was assumed. The use of the notation KT is restricted for $\mathrm{HF}$ and approximate HF methods (such as AM1 method) in this work, while mKT is reserved for the case of DFT, in which $-\varepsilon$ of Kohn-Sham orbitals is used to approximate VIPs. The calculated results are compared to each other. Total energy (E) in DFT is exact in the sense that it includes "correlation energy", while total energy in HF theory does not contain the correlation energy. Because of this, $\Delta \mathrm{E}$ method works well in DFT for calculation such as ionization energy of a system, in which $\Delta \mathrm{E}$ is the difference of total energies between ionized and neutral molecules.

CEBEs of aniline, nitrobenzene, $p$-nitroaniline, and uracil were calculated by HAM/3 and DFT with the $\Delta \mathrm{E}$ method. The ADF package was used for the DFT calculations. In all DFT calculations with ADF, we used the exchange-correlation potential labeled as PW86-PW91, made from Perdew-Wang 1986 exchange functional ${ }^{20}$ and Perdew-Wang 1991 correlation functional. ${ }^{21}$ Basis set of triple zeta plus one polarization, TZP, was used. This model can be expressed as $\Delta \mathrm{E}_{\mathrm{KS}}(\mathrm{PW} 86-\mathrm{W} 91) / \mathrm{TZP}$. Experimental CEBEs of uracil were observed in solid-state. CEBE (solid) and $\mathrm{CEBE}$ (gas) can be related by equation 1 ,

$\mathrm{CEBE}($ gas $)=\mathrm{CEBE}($ solid $)+\mathrm{WD}$

where WD (W for work function and D for delta, other energies) is energy shift due to solid-state effects. We adopt molecular solids model. We estimate WD to be average absolute deviation between calculated CEBE (gas) and observed CEBE (solid). The results were compared with those observed and those calculated with nonempirical DFT and HAM/3. Experimental geometry was used for $\mathrm{H}_{2} \mathrm{O}$ and uracil. Molecular geometries were calculated for the remaining molecules with $\mathrm{HF} / 6-31 \mathrm{G}^{*}$.

\section{Results and Discussion}

Table 1 summarizes VIPs of a total of 30 cases originating from the nine small molecules, calculated by the seven 
different models; (1) HAM/3(rDI), (2) HAM/3(- $\left.\varepsilon_{\mathrm{k}}\right)$, (3) uDI(B88-P86)/cc-pVTZ, (4) DFT (B88-P86)/cc-pVTZ(- $\left.\varepsilon_{\mathrm{k}}\right)$, (5) $-\varepsilon$ (SAOP)/TZP, (6) HF/cc-pVTZ, and (7) AM1. In case of $\mathrm{H}_{2} \mathrm{O}$, for example, all models, except the models (2) and (4), reproduce experimentally obtained vertical ionization energies fairly satisfactorily for the lowest three energies corresponding to $1 b_{1}, 3 a_{1}$ and $1 b_{2}$. However, the error of the calculated VIP for the low-lying $2 \mathrm{a}_{1}$ orbital by both HF and AM1 is more than $4 \mathrm{eV}$ (see Figure 1). Errors of (1) HAM/3 (rDI) and the two DFT models, (3) uDI and (4) SAOP, for the same event are much smaller than $4 \mathrm{eV}$. In DFT, the error due to correlation effect is expected to be small. The fact that the large errors registered in $\operatorname{VIP}\left(2 \mathrm{a}_{1}\right)$ by HF and AM1 may be due to mainly electron correlation effect, since no correlation effect is taken into account in HF methods. In case of the two models, (2) HAM/3 $\left(-\varepsilon_{\mathrm{k}}\right)$ and (4) DFT (B88P86)/cc-pVTZ $\left(-\varepsilon_{\mathrm{k}}\right)$, the discrepancy between experimental ionization potentials and corresponding negative values of k-th molecular orbital energy $\left(-\varepsilon_{\mathrm{k}}\right)$ of the neutral form of $\mathrm{H}_{2} \mathrm{O}$ is very large. The $-\varepsilon_{\mathrm{k}}$ values in the two models are uniformly smaller than the experimental ionization potentials by approximately $5 \mathrm{eV}$. The numerical $-\varepsilon_{\mathrm{k}}$ values in the models (2) are fairly close to those in the model (4). Situations similar to those seen in $\mathrm{H}_{2} \mathrm{O}$ can be observed in

Table 1.Ionization potentials (in eV) of nine small molecules calculated by seven different models; (1) HAM/3(rDI), (2) HAM/3(- $\varepsilon_{k}$ ), (3) $\mathrm{uDI}(\mathrm{B} 88-\mathrm{P} 86) / \mathrm{cc}-\mathrm{pVTZ}$, (4) DFT (B88-P86)/cc-pVTZ(- $\varepsilon_{\mathrm{k}}$ ) (5) $-\varepsilon$ (SAOP)/TZP, (6) HF/cc-pVTZ, and (7) AM1. Average absolute deviations (AAD's) are listed in the last row of the table. rDI and uDI are the two transition state methods. $-\varepsilon_{\mathrm{k}}$ signifies negative of orbital energy of a neutral molecule. KT signifies Koopmans's theorem

\begin{tabular}{|c|c|c|c|c|c|c|c|c|}
\hline MO & Exp. & $\begin{array}{c}\text { (1) HAM/3 } \\
\text { (rDI) }\end{array}$ & $\begin{array}{c}(2) \mathrm{HAM} / 3 \\
\left(-\varepsilon_{\mathrm{k}}\right)\end{array}$ & $\begin{array}{c}\text { (3)uDI(B88- } \\
\text { (P86)/cc-pVTZ }\end{array}$ & $\begin{array}{c}(4) \mathrm{DFT} /(\mathrm{B} 88- \\
\mathrm{P} 86) / \mathrm{cc}-\mathrm{p} V T Z \\
\left(-\varepsilon_{\mathrm{k}}\right)\end{array}$ & $\begin{array}{c}(5)-\varepsilon(\text { SAOP }) \\
/ \mathrm{TZP} \\
\left(-\varepsilon_{\mathrm{k}}\right)\end{array}$ & $\begin{array}{c}(6) \mathrm{HF} / \\
\text { cc-pVTZ } \\
\text { KT }\end{array}$ & $\begin{array}{l}\text { (7)AM1 } \\
\text { KT }\end{array}$ \\
\hline \multicolumn{9}{|l|}{$\mathrm{H}_{2} \mathrm{O}^{44}$} \\
\hline $1 b_{1}$ & 12.62 & 12.95 & 7.62 & 12.99 & 6.94 & 12.37 & 13.73 & 12.46 \\
\hline $3 a_{1}$ & 14.74 & 15.38 & 10.19 & 15.02 & 9.06 & 14.31 & 15.69 & 14.87 \\
\hline $1 b_{2}$ & 18.51 & 18.33 & 13.24 & 19.21 & 13.09 & 17.95 & 19.37 & 18.33 \\
\hline \multicolumn{9}{|l|}{$\mathrm{HF}^{45,46}$} \\
\hline $1 \pi$ & 16.19 & 16.82 & 9.85 & 16.33 & 9.30 & 15.68 & 17.50 & 13.99 \\
\hline $3 \sigma$ & 19.82 & 19.80 & 13.15 & 20.00 & 13.23 & 19.18 & 20.69 & 17.10 \\
\hline $2 \sigma$ & 39.58 & 39.66 & 32.63 & 36.80 & 29.83 & 36.05 & 43.39 & 48.17 \\
\hline \multicolumn{9}{|l|}{$\mathrm{NH}_{3}^{47,48}$} \\
\hline $3 a_{1}$ & 10.85 & 10.72 & 6.38 & 11.14 & 5.96 & 10.68 & 11.55 & 10.57 \\
\hline $1 \mathrm{e}^{\mathrm{T}}$ & 15.8 & 16.58 & 12.35 & 16.59 & 11.23 & 15.64 & 16.97 & 15.74 \\
\hline $2 a_{1}$ & 27.7 & 28.04 & 23.63 & 26.64 & 21.15 & 25.59 & 30.90 & 32.50 \\
\hline \multicolumn{9}{|l|}{$\mathrm{CH}_{4}$} \\
\hline $1 t_{2}{ }^{4}$ & 14.4 & 14.49 & 10.82 & 14.26 & 9.60 & 13.85 & 14.84 & 13.44 \\
\hline \multicolumn{8}{|l|}{$\mathrm{CO}$} & 29.37 \\
\hline $5 \sigma$ & 14.01 & 14.11 & 9.11 & 14.04 & 9.09 & 13.74 & 15.07 & 13.12 \\
\hline $1 \pi$ & 16.91 & 16.76 & 11.35 & 17.41 & 11.86 & 16.53 & 17.39 & 16.90 \\
\hline $4 \sigma$ & 19.72 & 19.73 & 14.22 & 19.70 & 14.19 & 18.97 & 21.87 & 22.10 \\
\hline \multicolumn{9}{|l|}{$\mathrm{CO}_{2}$} \\
\hline $1 \pi_{\mathrm{g}}$ & 13.79 & 13.74 & 9.21 & 13.86 & 9.05 & 14.42 & 14.76 & 13.30 \\
\hline $1 \pi_{\mathrm{u}}^{\mathrm{g}}$ & 17.60 & 17.69 & 13.08 & 17.51 & 12.69 & 17.83 & 19.37 & 18.50 \\
\hline $3 \sigma_{u}^{u}$ & 18.08 & 17.95 & 13.33 & 17.53 & 12.71 & 17.89 & 20.15 & 18.74 \\
\hline $4 \sigma_{g}$ & 19.40 & 19.47 & 14.85 & 18.59 & 13.84 & 19.09 & 21.74 & 22.68 \\
\hline \multicolumn{9}{|l|}{$\mathrm{N}_{2}^{\mathrm{g}}$} \\
\hline $3 \sigma_{g}$ & 15.60 & 15.43 & 10.16 & 15.68 & 10.32 & 15.23 & 16.66 & 14.30 \\
\hline $1 \pi_{\mathrm{u}}^{\mathrm{g}}$ & 16.98 & 16.21 & 10.90 & 17.19 & 11.60 & 16.44 & 17.21 & 16.31 \\
\hline $2 \sigma_{\mathrm{u}}^{\mathrm{u}}$ & 18.78 & 18.40 & 13.14 & 18.82 & 13.51 & 18.54 & 21.16 & 21.40 \\
\hline \multicolumn{9}{|l|}{$\mathrm{F}_{2}{ }^{\mathrm{u}}$} \\
\hline $1 \pi_{g}$ & 15.87 & 16.43 & 10.30 & 15.49 & 9.36 & 15.80 & 18.09 & 14.23 \\
\hline $1 \pi_{\mathrm{u}}^{\mathrm{g}}$ & 18.8 & 19.41 & 13.18 & 18.81 & 12.74 & 19.04 & 20.40 & 17.57 \\
\hline $\begin{array}{l}3 \sigma_{\mathrm{g}}^{\mathrm{u}} \\
\mathrm{H}_{2} \mathrm{CO}\end{array}$ & 21.1 & 20.72 & 14.50 & 21.51 & 15.35 & 21.29 & 22.02 & 19.41 \\
\hline $2 b_{2}$ & 10.89 & 10.78 & 6.39 & 10.73 & 6.15 & 11.01 & 12.04 & 10.77 \\
\hline $1 b_{1}^{2}$ & 14.5 & 14.85 & 10.32 & 16.25 & 9.99 & 14.51 & 14.46 & 14.74 \\
\hline $5 a_{1}$ & 16.0 & 16.45 & 11.85 & 16.36 & 10.87 & 15.49 & 17.56 & 16.16 \\
\hline $1 b_{2}$ & 16.6 & 17.59 & 13.50 & 17.69 & 12.32 & 16.81 & 18.98 & 17.46 \\
\hline $4 a_{1}^{2}$ & 21.8 & 21.31 & 17.26 & 19.86 & 15.70 & 20.27 & 23.55 & 25.00 \\
\hline AAD & $(0)$ & 0.34 & 4.94 & 0.57 & 5.62 & 0.65 & 1.61 & 1.83 \\
\hline
\end{tabular}




\section{$\mathrm{H}_{2} \mathrm{O}$ : IONIZATION POTENTIAL}

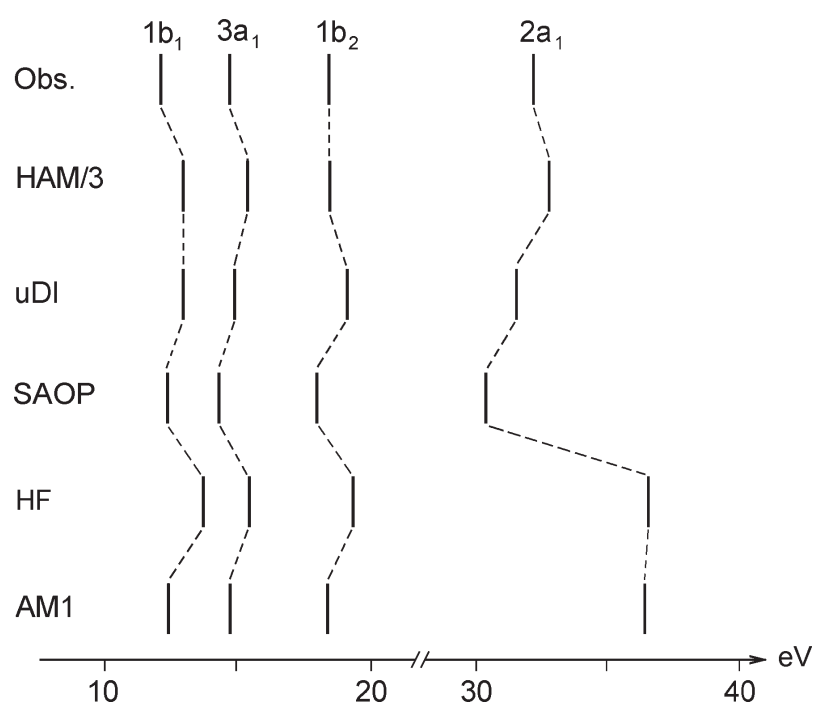

Figure 1. Comparison of vertical ionization potentials of $\mathrm{H}_{2} \mathrm{O}$ calculated with five different methods; HAM/3 (rDI), uDI, SAOP, HF and AM1.

the remaining eight small molecules in the Table 1 . The AADs obtained for the 30 cases in Table 1 of the seven different models, (1)-(7), are (1) $0.34 \mathrm{eV}$, (2) $4.94 \mathrm{eV}$, (3) 0.57 $\mathrm{eV}$, (4) $5.62 \mathrm{eV},(5) 0.65 \mathrm{eV},(6) 1.61 \mathrm{eV}$, and (7) $1.83 \mathrm{eV}$. AADs of the models (1) HAM/3 (rDI) and the two nonempirical DFT models, (3) uDI and (5) SAOP, are less than half of those of (6) HF and (7) AM1 models. On the other hand, AAD of the model (2) HAM/3 $\left(-\varepsilon_{\mathrm{k}}\right)$ is $4.94 \mathrm{eV}$, while that of the model (4) DFT (B88-P86)/cc-pVTZ(- $\left.\varepsilon_{\mathrm{k}}\right)$ is $5.62 \mathrm{eV}$. The two models gives close AAD values to each other indicating the similarity of the model (2) to the model (4). Because the existence of the close parallelism in the numerical values in the pair of the two models (2) and (4), at the same time in the other pair of the two models, (1) and (3), HAM/3 can be considered as a semiempirical version of nonempirical DFT (B88-P86)/cc-pVTZ. On the other hand, AM1 semiempirical method reproduces VIPs of ab initio HF method well. This is because AM1 is a semiempirical version of HF method, and not that of DFT. The model (5) $-\varepsilon(\mathrm{SAOP}) / \mathrm{TZP}$ resulted AAD of $0.65 \mathrm{eV}$, which is to be compared with AAD of 1.61 eV resulted from (6) ab initio HF/cc-pVTZ (KT). The model $-\varepsilon(\mathrm{SAOP})$ with nonempirical DFT is superior to KT in $a b$ initio $\mathrm{HF}$.

Since the model (2) HAM/3 $\left(-\varepsilon_{\mathrm{k}}\right)$ and the model (4) DFT (B88-P86)/cc-pVTZ $\left(-\varepsilon_{\mathrm{k}}\right)$ resulted large systematic errors for calculating VIP's of the small molecules in Table 1, we shall not consider them any further and work only with the remaining five models for the rest of discussions. Table 2 compares 13 lowest VIPs of uracil calculated by the five different models. The experimental VIPs were observed in gas-phase. ${ }^{39}$ Only the five lowest ionization events (5a", 24a', 4a", 23a', and 3a") have been assigned. AAD, corresponding only to the five lowest ionization events, of HAM/3 (rDI) is ca. $0.2 \mathrm{eV}$, while AADs of the three models, uDI, SAOP, and AM1, are in the neighborhood of $1 \mathrm{eV}$. AAD of HF is ca. $1.5 \mathrm{eV}$. If the 13 ionization events are taken into account (based on the ordering of HAM/3 and SAOP), the AADs take the values of $0.19 \mathrm{eV}$ (HAM/3), $0.80 \mathrm{eV}(\mathrm{uDI}), 0.94 \mathrm{eV}$ (SAOP), $2.20 \mathrm{eV}(\mathrm{HF})$ and $1.27 \mathrm{eV}$ (AM1). AAD of HAM/3 (rDI) is the smallest; AADs of the

Table 2. Ionization energies (in eV) of uracil calculated by HAM/3 (rDI), uDI, SAOP, HF, and AM1. Average absolute deviations (AAD's) are listed in the last row of the table

\begin{tabular}{|c|c|c|c|c|c|c|}
\hline MO & Exp. $^{a}$ & HAM/3(rDI) & uDI(B88-P86)/cc-pVTZ & $-\varepsilon(\mathrm{SAOP}) / \mathrm{TZP}$ & $\mathrm{HF} / \mathrm{cc}-\mathrm{pVTZ}$ & AM1 \\
\hline $5 a "$ & 9.59 & 9.83 & 8.92 & 10.95 & 10.11 & 10.09 \\
\hline $24 a^{\prime}$ & 10.12 & 10.22 & 9.14 & 11.00 & 12.15 & 11.41 \\
\hline $4 a "$ & 10.56 & 10.52 & 9.77 & 11.73 & 11.79 & 11.17 \\
\hline $23 a^{\prime}$ & 11.00 & 10.70 & 9.82 & 11.81 & 13.08 & 12.16 \\
\hline $3 a "$ & 12.63 & 12.44 & 11.93 & 13.63 & 14.11 & 13.32 \\
\hline $\mathrm{AAD}$ & $(0)$ & $(0.17)$ & $(0.86)$ & $(1.04)$ & $(1.47)$ & $(0.85)$ \\
\hline $2 \mathrm{a} "$ & (13.3) & 13.62 & 12.94 & 14.62 & 15.47 & 15.18 \\
\hline $22 a^{\prime}$ & $(14.0)$ & 14.07 & 13.03 & 14.81 & 16.41 & 14.74 \\
\hline $21 a^{\prime}$ & $(14.3)$ & 14.43 & 13.24 & 14.95 & 16.77 & 15.03 \\
\hline $20 a^{\prime}$ & $(14.6)$ & 14.97 & 13.91 & 15.70 & 17.74 & 16.45 \\
\hline 19a' & $(15.2)$ & 15.21 & 14.62 & 16.23 & 18.42 & 17.25 \\
\hline 1a” & $(15.7)$ & 15.28 & 14.77 & 16.36 & 17.95 & 17.08 \\
\hline $18 a^{\prime}$ & $(16.8)$ & 17.09 & 15.99 & 17.45 & 19.42 & 18.45 \\
\hline $17 a^{\prime}$ & $(17.6)$ & 17.30 & 16.94 & 18.31 & 20.63 & 19.56 \\
\hline AAD(all) & (0) & 0.19 & 0.80 & 0.94 & 2.20 & 1.27 \\
\hline
\end{tabular}

aThe experimental VIPs were observed in gas-phase. The values in parentheses are those read from photoelectron spectrum of uracil in the literature (Reference 39). 
two DFT models are close to each other; and AAD of HF is more than twice to those of DFT. In other words, VIPs calculated with $\mathrm{rDI}$ in HAM/3 and the two nonempirical DFT models are closer to observed values than those calculated with KT in $a b$ initio $\mathrm{HF}$. The spectral patterns for the five lowest ionization events obtained by $\mathrm{HAM} / 3$ $(\mathrm{rDI}), \mathrm{uDI}$ and SAOP reproduce that observed fairly well (see Figure 2). AM1 results parallel closely to those of HF, but neither reproduces the observed spectral pattern well.

Shapley and Chong ${ }^{40}$ calculated VIPs of $\mathrm{C}_{2} \mathrm{~F}_{4}$ with $\Delta \mathrm{E}$ approach using seven different DFT exchange-correlation functionals. Most AADs were in the neighborhood of $1.5 \mathrm{eV}$.

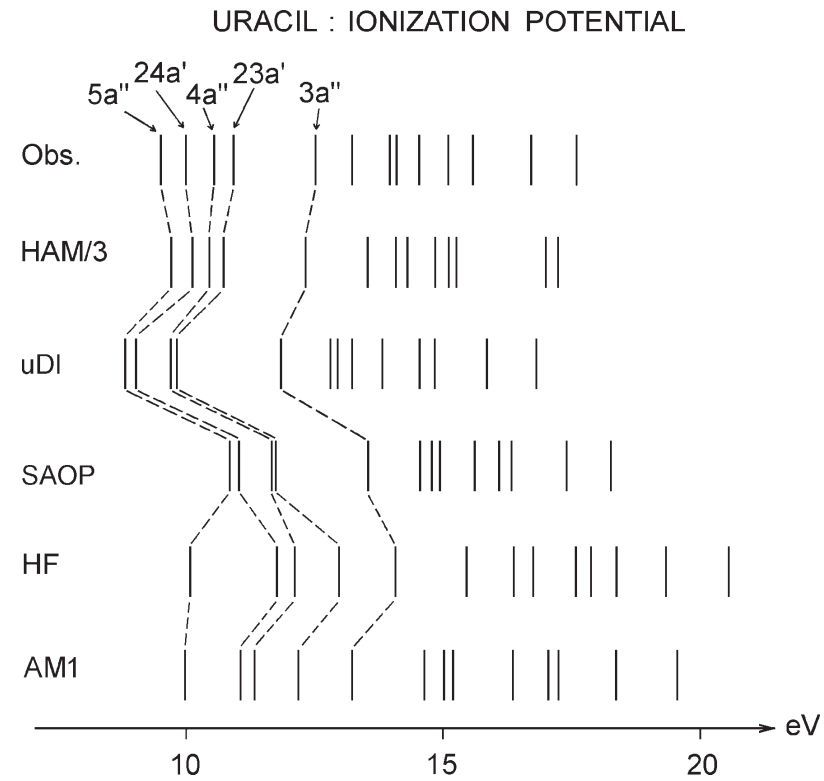

Figure 2. Comparison of vertical ionization potentials of uracil calculated with five different methods; HAM/3 (rDI), uDI, SAOP, HF and AM1.
The smallest AAD attained was $0.79 \mathrm{eV}$. We wanted to know if any one of our five methods can give better result than this. Table 3 lists VIPs of $\mathrm{C}_{2} \mathrm{~F}_{4}$ calculated with the five different methods. The value of AAD increases in the order $\mathrm{HAM} / 3$ (rDI) < SAOP < AM1 < UDI < HF. The smallest AAD, $0.27 \mathrm{eV}$, is registered by the semiempirical HAM/3 (rDI) method. This may be because $\mathrm{C}_{2} \mathrm{~F}_{4}$ is one of the molecules that were used for parametrization of the method. Next, the SAOP model gave AAD of $0.36 \mathrm{eV}$, which is much smaller than $1.5 \mathrm{eV}$. In fact, Chong et al. ${ }^{23}$ obtained AAD of $0.35 \mathrm{eV}$ with SAOP model for calculated VIPs of ten perhalo molecules. Our result is just a confirmation of the success of the SAOP model. The semiempirical AM1 showed AAD of $0.77 \mathrm{eV}$. The AAD of nonempirical $\mathrm{UDI}$ and $a b$ initio $\mathrm{HF}$ showed larger AAD values, more than 1.5 eV's. B88-P86 functional used in the uDI calculation was not appropriate for the type of molecule. Sharpley and Chong ${ }^{40}$ obtained similar results as our uDI result using various other types of functionals. The $-\varepsilon(\mathrm{SAOP}) / \mathrm{TZP}$ model proved to be a good choice for this type of molecules, as found earlier. ${ }^{23}$ Error due to correlation effect, together with the approximate nature of $\mathrm{KT}$, is large in $\mathrm{HF}$ method for $\mathrm{C}_{2} \mathrm{~F}_{4}$.

Table 4 lists CEBEs of substituted benzenes $\left(\mathrm{X}-\mathrm{C}_{6} \mathrm{H}_{4}-\mathrm{Y}\right)$ such as benzene, aniline, nitrobenzene and $p$-nitroaniline calculated with $H A M / 3$ and with $\Delta \mathrm{E}_{\mathrm{KS}}$ (PW86-PW91)/TZPADF models. AAD obtained with HAM/3 is $3.25 \mathrm{eV}$, which is much larger than $0.14 \mathrm{eV}$, the AAD obtained with the nonempirical DFT calculations. The $\Delta \mathrm{E}_{\mathrm{KS}}$ (PW86-PW91)/ TZP method works very well. ${ }^{41} \mathrm{AAD}$ of $0.15 \mathrm{eV}$ had also been obtained previously for exactly the same set of molecules using the uGTS model. ${ }^{42}$ The DeMon DFT program was employed in the uGTS calculations. We designate this as uGTS(DeMon) model. Both $\Delta \mathrm{E}_{\mathrm{KS}}$ (PW86PW91)/TZP(ADF) method and the uGTS(DeMon) model

Table 3. Ionization potentials (in eV) of $\mathrm{C}_{2} \mathrm{~F}_{4}$ calculated by HAM/3 (rDI), uDI, SAOP, HF, and AM1. Average absolute deviations (AAD's) are listed in the last row of the table

\begin{tabular}{|c|c|c|c|c|c|c|}
\hline MO & $\operatorname{Exp}^{\text {a }}$ & $\mathrm{HAM} / 3(\mathrm{rDI})$ & uDI(B88-P86)/cc-pVTZ & $-\varepsilon(\mathrm{SAOP}) / \mathrm{TZP}$ & $\mathrm{HF} / \mathrm{cc}-\mathrm{pVTZ}$ & AM1 \\
\hline $2 b_{3 u}$ & 10.69 & 10.94 & 9.96 & 11.10 & 10.81 & 10.19 \\
\hline $4 b_{3 g}$ & 15.9 & 16.14 & 14.32 & 15.75 & 18.42 & 15.42 \\
\hline $6 a_{1 g}^{3 g}$ & 16.6 & 16.47 & 14.85 & 16.12 & 18.91 & 14.41 \\
\hline $4 b_{2 u}^{1 g}$ & 16.6 & 16.29 & 14.89 & 16.27 & 19.26 & 15.43 \\
\hline $1 \mathrm{a}_{\mathrm{u}}^{2 \mathrm{u}}$ & 16.6 & 16.45 & 14.94 & 16.41 & 19.48 & 15.83 \\
\hline $1 \mathrm{~b} 1 \mathrm{~g}$ & 16.6 & 16.52 & 15.10 & 16.56 & 20.18 & 15.93 \\
\hline $5 b_{1 u}$ & 17.6 & 17.48 & 15.74 & 17.10 & 20.91 & 16.52 \\
\hline $1 b_{2 g}$ & 18.2 & 17.76 & 16.50 & 17.84 & 21.72 & 17.82 \\
\hline $1 \mathrm{~b}_{3 \mathrm{u}}^{2 \mathrm{~g}}$ & 19.4 & 19.45 & 17.73 & 18.93 & 22.10 & 19.92 \\
\hline $3 b_{3 \mathrm{su}}^{3 \mathrm{u}}$ & 19.4 & 19.82 & 18.24 & 19.24 & 23.18 & 18.39 \\
\hline $3 b_{2 u}^{3 g}$ & 21.0 & 20.37 & 19.39 & 20.33 & 23.854 & 20.61 \\
\hline $5 \mathrm{a}_{\mathrm{g}} \mathrm{au}^{\mathrm{u}}$ & 21.0 & 20.61 & 19.54 & 20.43 & 25.18 & 20.88 \\
\hline $\mathrm{AAD}$ & $(0)$ & 0.27 & 1.53 & 0.36 & 2.87 & 0.77 \\
\hline
\end{tabular}

${ }^{\text {aReference } 49 .}$ 
Table 4. Calculated core-electron binding energies (in eV) for benzene $\left(\mathrm{C}_{6} \mathrm{H}_{6}\right)$, aniline $\left(\mathrm{C}_{6} \mathrm{H}_{5}-\mathrm{NH}_{2}\right)$, nitrobenzene $\left(\mathrm{C}_{6} \mathrm{H}_{5}-\mathrm{NO}_{2}\right)$, and $p$-nitroaniline $\left(p-\mathrm{NH}_{2}-\mathrm{C}_{6} \mathrm{H}_{4}-\mathrm{NO}_{2}\right)$, using $\mathrm{HAM} / 3$, and density functional theory with TZP basis sets and PW86x-PW91c functional. The $\Delta \mathrm{E}$ method was employed. Absolute deviations (AD) from experiment are given in parenthesis immediately after calculated CEBEs

\begin{tabular}{|c|c|c|c|c|}
\hline Molecule & Core hole & $\mathrm{HAM} / 3$ & $\Delta \mathrm{E}_{\mathrm{KS}}(\mathrm{PW} 86-\mathrm{PW} 91) / \mathrm{TZP}$ & Observed $^{50-53}$ \\
\hline $\mathrm{C}_{6} \mathrm{H}_{6}$ & $\mathrm{C}$ & $286.20(4.21)$ & $290.44(0.03)$ & 290.41 \\
\hline \multirow{5}{*}{$\mathrm{C}_{6} \mathrm{H}_{5}-\mathrm{NH}_{2}$} & $\mathrm{C} 1$ & $288.32(2.97)$ & 291.38(0.09) & 291.29 \\
\hline & $\mathrm{C} 2$ & $286.11(3.84)$ & $289.99(0.04)$ & 289.95 \\
\hline & $\mathrm{C} 3$ & $285.94(4.31)$ & $290.17(0.08)$ & 290.25 \\
\hline & $\mathrm{C} 4$ & $285.84(4.01)$ & $289.82(0.03)$ & 289.85 \\
\hline & $\mathrm{N}$ & $401.21(4.17)$ & $405.49(0.11)$ & 405.38 \\
\hline \multirow[t]{6}{*}{$\mathrm{C}_{6} \mathrm{H}_{5}-\mathrm{NO}_{2}$} & $\mathrm{C} 1$ & $289.88(2.21)$ & $292.06(0.03)$ & 292.09 \\
\hline & $\mathrm{C} 2$ & $287.26(4.04)$ & $291.29(0.01)$ & 291.3 \\
\hline & $\mathrm{C} 3$ & $287.01(3.99)$ & $291.19(0.19)$ & 291.0 \\
\hline & $\mathrm{C} 4$ & $286.98(4.12)$ & $291.21(0.11)$ & 291.1 \\
\hline & $\mathrm{N}$ & $409.22(2.42)$ & $411.35(0.29)$ & 411.64 \\
\hline & $\mathrm{O}$ & $537.85(0.60)$ & $538.48(0.03)$ & 538.45 \\
\hline \multirow{8}{*}{$p-\mathrm{NH}_{2}-\mathrm{C}_{6} \mathrm{H}_{4}-\mathrm{NO}_{2}$} & $\mathrm{C} 1\left(-\mathrm{NH}_{2}\right)$ & 289.12 & 292.23 & \\
\hline & $\mathrm{C} 2$ & 286.75 & 290.64 & \\
\hline & C3 & 286.78 & 290.91 & \\
\hline & $\mathrm{C} 4\left(-\mathrm{NO}_{2}\right)$ & 289.26 & 291.30 & \\
\hline & $\mathrm{C}(\text { average })^{\mathrm{a}}$ & $287.57(3.53)$ & $291.11(0.01)$ & 291.1 \\
\hline & $\mathrm{N}\left(\right.$ in $\left.\mathrm{NO}_{2}\right)$ & $408.34(2.86)$ & $410.39(0.81)$ & 411.2 \\
\hline & $\mathrm{N}\left(\right.$ in $\left.\mathrm{NH}_{2}\right)$ & $402.06(0.82)$ & $406.23(0.23)$ & 406.0 \\
\hline & $\mathrm{O}\left(\right.$ in $\left.\mathrm{NO}_{2}\right)$ & $537.08(3.94)$ & $537.68(0.22)$ & 537.9 \\
\hline AAD & & $(3.25)$ & $(0.14)$ & (0) \\
\hline
\end{tabular}

${ }^{\mathrm{a}} \mathrm{CEBEs}$ for carbons of $p-\mathrm{NH}_{2}-\mathrm{C}_{6} \mathrm{H}_{4}-\mathrm{NO}_{2}$ are averaged over four types of carbon.

resulted almost the same AAD. Although the quality of the two models is equivalent, one major difference is the presence/absence of a fortuitous partial cancellation between model error and functional error, making the $\Delta \mathrm{E}_{\mathrm{KS}}$ method more reliable conceptually. On the other hand, the main difference between the two programs DeMon and $\mathrm{ADF}$ resides on efficiency. $\Delta \mathrm{E}_{\mathrm{KS}}$ (PW86-PW91)/TZP using ADF is almost five- to ten-fold more efficient than the uGTS(DeMon) model, or $\Delta \mathrm{E}_{\mathrm{KS}}$ (PW86-PW91)/cc$\mathrm{pCVTZ}$ (DeMon) method. It should be mentioned that $\Delta \mathrm{E}_{\mathrm{KS}}$ (PW86-PW91)/cc-pCVTZ(DeMon) gives almost identical CEBEs as $\Delta \mathrm{E}_{\mathrm{KS}}$ (PW86-PW91)/TZP(ADF), but much less efficiently. On the other hand, CEBEs calculated with HAM/3 are uniformly shifted toward smaller values with respect to the observed values by approximately $4 \mathrm{eV}$, in case of carbon atoms. Table 5 lists chemical shift $\triangle \mathrm{CEBE}$, defined by equation 2 ,

$$
\Delta \mathrm{CEBE}=\mathrm{CEBE}\left(\mathrm{X}-\mathrm{C}_{6} \mathrm{H}_{4}-\mathrm{Y}\right)-\mathrm{CEBE}\left(\mathrm{H}-\mathrm{C}_{6} \mathrm{H}_{4}-\mathrm{H}\right)
$$

$\triangle \mathrm{CEBE}$ is the difference between CEBE of an atom in a substituted benzene and CEBE of the corresponding atom of unsubstituted benzene (the reference molecule). $\triangle \mathrm{CEBE}$ at $\mathrm{C} 1$ atom is positive in the two molecules with the values of $c a .+0.9 \mathrm{eV}$ in case of aniline and $c a .+1.7 \mathrm{eV}$ in nitrobenzene. These large positive shifts are due to the substituent, either $-\mathrm{NH}_{2}$ or $-\mathrm{NO}_{2}$, at $\mathrm{C} 1$ position. The $\triangle \mathrm{CEBEs}$ at $\mathrm{C} 2, \mathrm{C} 3$ and $\mathrm{C} 4$ atoms are negative in aniline because $-\mathrm{NH}_{2}$ has strong electron donating nature. Electron density increases at $\mathrm{C} 2, \mathrm{C} 3$ and $\mathrm{C} 4$ in the phenyl ring that causes destabilization of the core electrons. Absolute value of shift increases in the order $\mathrm{C} 3<\mathrm{C} 2<\mathrm{C} 4$. This is due to the fact that the electron donating effect of $-\mathrm{NH}_{2}$ in aniline increases in the order: $\mathrm{C} 3<\mathrm{C} 2<\mathrm{C} 4$. Nonempirical DFT results reproduce the observed results of $\triangle \mathrm{CEBEs}$ and tendency very well (see Figure 3 ). HAM/ 3 resulted $\Delta$ CEBE for $\mathrm{C} 1$ position too large, by more than $1 \mathrm{eV}$, in comparison to the observed value. $\triangle \mathrm{CEBEs}$ of $\mathrm{HAM} / 3$ at $\mathrm{C} 2, \mathrm{C} 3$ and $\mathrm{C} 4$ atoms are approximately equal to those of observed values. However, the order of shift is $\mathrm{C} 2<\mathrm{C} 3<\mathrm{C} 4$, disagreeing with the observed order of $\mathrm{C} 3<\mathrm{C} 2<\mathrm{C} 4$ (Figure 3). HAM/3 did not reproduce correctly the order. In the case of nitrobenzene, the signs of $\triangle \mathrm{CEBEs}$ at $\mathrm{C} 2, \mathrm{C} 3$ and $\mathrm{C} 4$ atoms are all positive. This is because $-\mathrm{NO}_{2}$ group has a strong electron withdrawing character. Electron density in the phenyl ring decrease because of $-\mathrm{NO}_{2}$. This stabilizes core electrons of the atoms in the ring causing the substantial increase of CEBEs. The magnitude of the shift 
Table 5. Observed and calculated chemical shifts $\triangle$ CEBEs (in eV), of carbon atoms in benzene ring of substituted benzenes $\left(\mathrm{C}_{6} \mathrm{H}_{5}-\mathrm{X}\right) . \Delta \mathrm{CEBEs}$ in the table have been calculated as the difference between CEBE of carbon atom in the substituted benzene and CEBE of the carbon atom in benzene (equation 2)

\begin{tabular}{|c|c|c|c|c|c|}
\hline Molecule & Hole, 1s & Observed & $\mathrm{HAM} / 3$ & $\Delta \mathrm{E}_{\mathrm{KS}}(\mathrm{PW} 86-\mathrm{PW} 91) / \mathrm{TZP}$ & Hammett $\sigma$ \\
\hline $\mathrm{C}_{6} \mathrm{H}_{5}-\mathrm{H}$ & $\mathrm{C}$ & 0.00 & 0.00 & 0.00 & 0.000 \\
\hline \multirow[t]{4}{*}{$\mathrm{C}_{6} \mathrm{H}_{5}-\mathrm{NH}_{2}$} & $\mathrm{C} 1$ & +0.88 & +2.12 & +0.94 & \\
\hline & $\mathrm{C} 2$ & -0.46 & -0.09 & -0.45 & \\
\hline & $\mathrm{C} 3$ & -0.16 & -0.26 & -0.27 & -0.161 \\
\hline & $\mathrm{C} 4$ & -0.56 & -0.36 & -0.62 & -0.660 \\
\hline \multirow{4}{*}{$\mathrm{C}_{6} \mathrm{H}_{5}-\mathrm{NO}_{2}$} & $\mathrm{C} 1$ & +1.68 & +3.68 & +1.62 & \\
\hline & $\mathrm{C} 2$ & +0.89 & +1.06 & +0.85 & \\
\hline & $\mathrm{C} 3$ & +0.59 & +0.81 & +0.75 & +0.710 \\
\hline & $\mathrm{C} 4$ & +0.69 & +0.78 & +0.77 & +0.778 \\
\hline \multirow{4}{*}{$\mathrm{NH}_{2}-\mathrm{C}_{6} \mathrm{H}_{4}-\mathrm{NO}_{2}$} & $\mathrm{C} 1$ & & +2.92 & +1.79 & \\
\hline & $\mathrm{C} 2$ & & +0.54 & +0.20 & \\
\hline & $\mathrm{C} 3$ & & +0.58 & +0.47 & \\
\hline & $\mathrm{C} 4$ & & +3.06 & +0.86 & \\
\hline
\end{tabular}

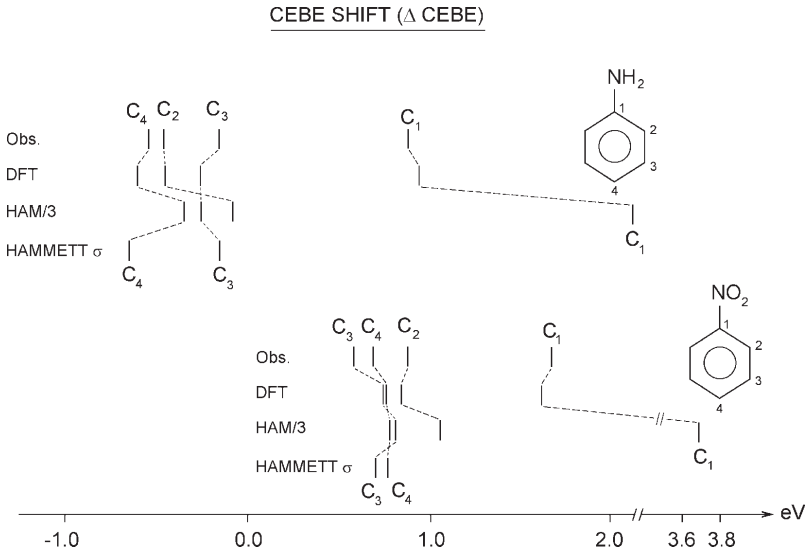

Figure 3. Comparison of CEBE shifts ( $\triangle$ CEBEs) of aniline and nitrobenzene calculated with nonempirical DFT and semiempirical HAM/3. Hammett sigma constants at meta $\left(\mathrm{C}_{3}\right)$ and para $\left(\mathrm{C}_{4}\right)$ positions are also included.

increases in the order $\mathrm{C} 3<\mathrm{C} 4<\mathrm{C} 2<\mathrm{C} 1$ (observed). The nonempirical DFT calculations reproduce the observed results fairly well. The HAM/3 $\triangle \mathrm{CEBE}$ at $\mathrm{C} 1$ atom are more than $2 \mathrm{eV}$ in error. However, $\triangle \mathrm{CEBE}$ values of C3, $\mathrm{C} 4$ and $\mathrm{C} 2$ are close to the observed ones. The order of shifts of $\mathrm{C} 3$ and $\mathrm{C} 4$ is inverted in HAM/3. Lindberg et al. ${ }^{43}$ had shown that $\triangle \mathrm{CEBE}$ correlate linearly to the Hammett sigma constants $(\sigma)$ in substituted benzenes. Good agreements between Hammett $\sigma$ 's and $\triangle$ CEBEs at C3 (meta-) and $\mathrm{C} 4$ (para-) positions in $\mathrm{C}_{6} \mathrm{H}_{5}-\mathrm{NO}_{2}$ can be seen in those observed, and calculated with DFT by $\Delta \mathrm{E}_{\mathrm{KS}}$ (PW86PW91)/TZP. Fairly good agreements are also obtained with $\mathrm{HAM} / 3$. This indicates a potential utility of $\mathrm{HAM} / 3$ in investigations of chemical reactivity and/or biological activity of series of molecules. When one works with a series of molecules studying relative chemical and/or biological activity, it is not necessary to have accurate CEBEs themselves, if reliable $\triangle \mathrm{CEBE}$ values are available. As far as we know, HAM/3 is the only semiempirical SCF method that is capable of calculating molecular CEBEs by $\Delta \mathrm{E}$ method. Consequently, calculations of $\triangle \mathrm{CEBEs}$ of medium and large molecular systems can be done conveniently with $\mathrm{HAM} / 3$.

Table 6 lists CEBEs of solid-state uracil calculated by equation 1 using CEBEs of gas-phase uracil calculated with $\Delta \mathrm{E}_{\mathrm{KS}}$ (PW86-PW91)/TZP-ADF model and HAM/3. In principle, there is only one true value of WD for the system we study. However, we adopted two empirical values of WDs (WD1 and WD2) for the two different theoretical methods. This is a consequence of the method of approximation of WD that we adopted. Nonempirical DFT

Table 6. Comparison of experimental CEBEs (in eV) of uracil and those calculated with $\Delta \mathrm{E}_{\mathrm{KS}}(\mathrm{PW} 86-\mathrm{PW} 91) / \mathrm{TZP}-\mathrm{ADF}$ and HAM/3 (equation 1)

\begin{tabular}{lccc}
\hline & Observed & $\begin{array}{c}\text { Calcd.-WD1 } \\
\text { DFT }\end{array}$ & $\begin{array}{c}\text { Calcd.-WD2 } \\
\text { HAM/3 }\end{array}$ \\
\hline C2 & 289.75 & 289.37 & 289.92 \\
C4 & 288.95 & 288.43 & 288.33 \\
C5 & 285.65 & 285.45 & 284.37 \\
C6 & 286.85 & 287.14 & 285.67 \\
N1 & 400.7 & 400.98 & 400.94 \\
N3 & 400.8 & 401.45 & 400.97 \\
O2 & 531.85 & 531.97 & 533.34 \\
O4 & 531.85 & 531.64 & 532.86 \\
AAD & 0 & 0.33 & 0.77 \\
WD & & 5.69 & 3.22 \\
\hline
\end{tabular}


resulted AADs of $0.33 \mathrm{eV}$ while $\mathrm{HAM} / 3$ of $0.77 \mathrm{eV}$, both of which are reasonable.

Although number of molecules and examples treated in this work is very limited, we can expect to obtain similar results for any other molecules and any number of examples. Within about a dozen examples studied, HAM/3 reproduced the VIP values obtained with nonempirical DFT more closely than those obtained with $\mathrm{KT}$ in $a b$ initio $\mathrm{HF}$. It should be noted that HAM/3 resulted the smallest AAD of calculation of VIPs among the five different approaches for the molecules treated (mainly because the semiempirical parameters in HAM/3 were chosen in such a way to reproduce observed VIPs).

The $-\varepsilon(\mathrm{SAOP}) / \mathrm{TZP}$ model consistently gave results similar to (or better than) uDI(B88-P86)/cc-pVTZ model for calculation of VIPs. This indicates superiority of the exchange-correlation potential $\mathrm{V}_{\mathrm{xc}}=\mathrm{SAOP}$ in comparison to B88-P86. The $-\varepsilon(\mathrm{SAOP}) / \mathrm{TZP}$ model is like KT, but for Kohn-Sham orbitals, and so we call it meta-Koopmans' theorem, or mKT. In other words, if one has accurate functionals, then there is no need for uDI or uTS model. It is because B88-P86 functional and most other functionals are poor, especially in the large-r region, that we need to use $\mathrm{uDI}$ (or uTS) model to get better results. It appears that $\mathrm{HAM} / 3$ is approximating such an approximate procedure. Therefore, strictly speaking, $\mathrm{HAM} / 3$ is not an approximation for DFT, but rather an approximation for the restricted diffuse ionization (rDI) model, which is an approximation used in some DFT calculations of VIPs. We demonstrated numerically that values and trend of VIPs calculated by HAM/3 reproduces those obtained by uDI(B88-P86)/cc-pVTZ and $-\varepsilon$ (SAOP)/TZP models.

In calculation of accurate CEBEs of the molecules, we confirmed high efficiency of the $\Delta \mathrm{E}_{\mathrm{KS}}$ (PW86-PW91)/TZP method. HAM/3 also calculates $\mathrm{CEBE}$ by $\triangle \mathrm{E}$, with even greater efficiency, but with errors of more than $3 \mathrm{eV}$. Hence, the present study of CEBEs based on HAM/3 and accurate DFT procedure cannot answer the question in the title of this work. Fortunately, the results showed that $\triangle \mathrm{CEBEs}$ (chemical shifts) obtained with HAM/3 are fairly close to the corresponding observed values. Hence, it may be useful for computational studies of relative chemical and/or biological activities of large systems.

\section{Acknowledgements}

We thank Dr. D.R. Salahub for an early version of the DeMon DFT program. One of us (YT) thanks Fundação de Amparo à Pesquisa do Estado de São Paulo (FAPESP ) for a research fund and Conselho Nacional de Desenvolvimento Científico e Tecnológico $(\mathrm{CNPq})$ for a research fellowship; and another author (DPC) is grateful to the Natural Sciences and Engineering Research Council (NSERC) of Canada for financial support.

\section{References}

1. Åsbrink, L.; Fridh, C.; Lindholm, E.; Chem. Phys. Lett. 1977, 52, 63; ibid. 1977, 52, 69; ibid. 1977, 52, 72; Åsbrink, L.; Fridh, C.; Lindholm, E.; de Bruijn, S.; ibid. 1979, 66, 411.

2. Åsbrink, L.; Fridh, C.; Lindholm, E.; Chem. Phys. 1978, 27, 159; ibid. 1978, 27, 169.

3. Lindholm, E.; Bieri, G.; Åsbrink, L.; Fridh, C.; Int. J. Quantum Chem. 1978, 14, 737; Åsbrink, L.; Fridh, C.; Lindholm, E.; J. Electron Spectrosc. Relat. Phenom. 1979, 16, 65; Åsbrink, L.; Fridh, C.; Lindholm, E.; Chong, D.P.; Chem. Phys. 1979, 43, 189.

4. Chong, D.P.; Theoret. Chim. Acta 1979, 51, 55; Can. J. Chem. 1980, 58, 1687.

5. Takahata, Y.; Int. J. Quantum Chem. 1986, 30, 453; J. Mol. Struct. (Theochem)1993, 283, 289; ibid. 1995, 335, 229.

6. Takahata, Y.; Hara, T.; Narita, S.; Shibuya, T.; J. Mol. Struct. (Theochem) 1998, 431, 219.

7. Takaoka, K.; Maeda, S.; Miura, H.; Otsuka, T.; Endo, K.; Chong,D.P.; Bull. Chem. Soc. Jpn. 2000, 73, 43.

8. Urch, D.S.; Bergknut, L.; Young, T.K.L.M.; Kim, R.S.; Chong, D.P.; Andermann, G.; Spect. Lett. 1980, 13, 487.

9. Chong, D.P.; Chem. Phys. Lett. 1981, 82, 511.

10. Chong, D.P.; Can. J. Chem. 1983, 61, 1.

11. Gardner, A.; Mukherjee, P.K.; Chong, D.P.; J. Mol. Struct.(Theochem), 1984, 108, 25.

12. Lindholm E.; Åsbrink L.; Molecular Orbitals and their Energies, Studied by the Semiempirical HAM Method, SpringVerlag: Berlin, 1985.

13. Hohemberg, P.; Kohn, W.; Phys. Rev. 1964, 136, B864.

14. Kohn, W.; Sham, L.J.; Phys. Rev. 1965, 140, A1133.

15. Parr, R.G.; Yang, W.; Density-Functional Theory of Atoms and Molecules, Oxford University Press: Oxford, 1989. p.234.

16. Slater, J.C.S.; Adv. Quantum Chem. 1972, 6, 1.

17. Duffy, P.; Chong, D.P.; Org. Mass Spectrom. 1993, 28, 321; Hu, C.-H.; Chong, D.P.; J. Chin. Chem. Soc. 2000, 47, 141; Caviglasso, C.; Chong, D.P. In Recent Advances in Density Functional Methods, Part III; Barone, V.; Bencini, A.; Fantucci, P.; eds., Word Scientific: London, 2002, p.80.

18. Becke, A.D.; Phys. Rev. A 1988, 38, 3098.

19. Perdew, J. P.; Phys. Rev. B 1986, 33, 8822.

20. Perdew, J. P.; Wang, Y.; Phys. Rev. B 1986, 33, 8800.

21. Perdew, P.J.; Kurth, S.; In Density Functionals: Theory and Applications; Joubert, D., ed.; Springer: Berlin, 1998.

22. Shapley, W.A.; Chong, D.P. ; Int. J. Quantum Chem. 2001, 81, 34.

23. Chong, D.P.; Aplincourt, P.; Bureau, C.; J. Phys. Chem. A 2002, 106, 356 
24. Siegbahn, K.; Nording, C.; Hedman, J.; Heden, P.F.; Hamrin, K.; Gelius, U.; Bergmark, T.; Werme, L.O.; Manne, R.; Baer, Y.; ESCA Applied to Free Molecules; North-Holland: Amsterdam, 1969.

25. Shirley, D.A.; Adv. Chem. Phys. 1973, 23, 85; Bahr, J.; Contemp. Phys. 1973, 4, 320; Jolly, W.L.; Coord. Chem. Rev. 1974, 13, 47; Gelius, U.; Physica Scripta 1974, 9, 133.; Basch, H.; J. Electron Spectrosc. Rel. Phenom. 1974, 5, 463.; Schwartz, M. E.; Schaefer, H. F.; ed., Application of Electronic Structure Theory; Plenum Press: New York, 1977, pp. 357-380.

26. Chong, D. P.; J. Mol. Sci. (Wuhan, China) 1982, 2, 55.

27. Chong, D.P.; Chem. Phys. Lett. 1995, 232, 486; Chong, D.P.; J. Chem. Phys. 1995, 103, 1842; Cavigliasso, G.; Chong, D.P.; Can. J. Chem. 1999, 77, 24.

28. Williams, A.R.; deGroot, R.A.; Sommers, C.B.; J. Chem. Phys. 1975, 63, 628.

29. Pulfer, M.; Hu, C.-H.; Chong, D.P.; Chem. Phys. 1997, 216, 91.

30. Cavigliasso, G.; Chong, D.P.; J. Chem.. Phys. 1999, 111, 9485.

31. Amant, A.; Salahub, D.R.; Chem. Phys. Lett. 1990, 169, 387

32. Chong, D.P. ; Aplincourt, P.; Bureau, C.; J. Phys. Chem. A 2002, 106, 356.

33. Chong, D.P. In Reviews in Modern Quantum Chemistry, A Celebration of the Contributions of R.G. Parr; Sen, K.D., ed., World Scientific Publishing Co.: Singapore, 2002, pp.11061139.

34. ADFProgram System, Releaase 2002.03, Scientific Computing \& Modelling NV, Amsterdam, 2000.

35. Roothaan, C. C. J.; Rev. Mod. Phys. 1951, 23, 69.

36. Dewar, M.J.S.; Zeobisch, E.G.; Healy, E.F.; Stewart, J.J.P.; J. Am. Chem. Soc. 1985, 107, 3902.

37. Åsbrink, L.; Fridh, C.; Lindholm, E.; QCPE (Quantum Chemistry Program Exchange) 1980, 12, 393.

38. Gaussian 94; Frish, M.J.; Trucks, G.W.; Schlegel, H.B.; Gill, P.M.W.; Johnson, B.G.; Robb, M.A.; Cheeseman, J.R.; Keith, T.A.; Peterson, G.A.; Montgomery, J.A.; Ragavachari, K. ; AlLaham, M.A.; Zakrzewski, V.G.; Ortiz, J.V.; Foresman, J.B.; Cisolwski, J.; Stefanov, B.B.; Nanayakkara, A.; Peng, C.Y.; Ayara, P.Y.; Chen, W. ; Wong, M.W. ; Andres, J.L.; Replogle, E.S; Gomperts, .R. ; Martin, R.L.; Fox, D.J.; Binkley, J.S. ; Defrees, D.J; Baker, J.; Stewart, J.P; Head-Gordon, M.; Gonzalez, C.; Pople, J.A., Gaussian, Inc.: Pittsburgh, PA, 1995.
39. Padva, A.; Le Breton, P.R.; Dinerstein R. J.; Riynard, J.N.A.; Biochem. Biophys. Res. Commun. 1974, 60, 1262; O'Donell, T.J.; Le Breton, P.R.; Shipman, L.L.; J. Phys. Chem. 1980, 84, 1975.

40. Shapley, W.A.; Chong, D.P. ; Int. J. Quantum Chem. 2001, 81, 34.

41. Takahata, Y.; Chong, D.P.; J. Electron Spectrosc. Relat. Phenom. 2003, 133, 69.

42. Takahata, Y.; Chong, D.P.; Bull. Chem. Soc. Jpn. 2000, 73, 2453.

43. Linderberg, B.; Svensson, S.; Malmquist, P. A.; Basilier, E.; Gelius U.; Siegbahn, K.; Chem. Phys. Lett. 1976, 40, 175.

44. Potts, A. W.; Price, W. C.; Proc. Roy. Soc. (London) 1972, A326, 181.

45. Bieri, G.; Schmelzer, A.; Asbrink, L.; Jonsson, M.; Chem. Phys. 1980, 49, 213.

46. Shaw, RW.; Thomas, T.D.; Phys. Rev. A 1975, 11, 1491.

47. Turner, D. W.; Baker, C.; Baker, A. D.; Brundle, C. R.; Molecular Photoelectron Spectroscopy, Wiley-Interscience: New York, 1971.

48. Bieri, G.; Asbrink, L.; von Niessen, W.; J. Electron. Spectrosc. Relat. Phenom. 1982, 27, 129.

49. Bieri, G.; Asbrink, L.; von Niessen, W.; J. Electron. Spectrosc. Relat. Phenom. 1981, 23, 281.

50. Linderberg, B.; Svensson, S.; Malmquist, P. A.; Basilier, E.; Gelius U.; Siegbahn, K.; Report UUIP-910, Uppsala University, Institute of Physics: Uppsala, Dec. 1975.

51. Ohta, T. ; Fujikawa, T.; Kuroda, H.; Bull. Chem. Soc. Jpn. 1975, 48, 2017.

52. Slaughter, A.R.; Banna, M.S.; McDowell, C.A.; Chem. Phys. Lett. 1983, 98, 531.

53. Jolly, W.L; Bomben, .K.D.; Eyermann, C.J.; At. Data Nucl. Data Tables 1984, 31, 434.

Received: April 17, 2003

Published on the web: March 24, 2004

FAPESP helped in meeting the publication costs of this article. 